\title{
Predictors of Pregnancy Outcome in Antiphospholipid Syndrome: A Review
}

Sara Tabacco ${ }^{1}$, Silvia Salvi ${ }^{2}$, De Carolis Sara ${ }^{2}$, Angela Botta ${ }^{2}$, Sergio Ferrazzani ${ }^{2}$, Garufi Cristina ${ }^{3}$, Benedetti Panici Pierluigi ${ }^{1}$, Lanzone Antonio ${ }^{2}$ and De Carolis Maria $\mathrm{Pia}^{4}$

${ }^{1}$ Department of Obstetrics and Gynaecology, Sapienza University, Rome, Italy

${ }^{2}$ Department of Obstetrics and Gynaecology, Catholic University of Rome, Italy

${ }^{3}$ Lupus Clinic, Department of Internal Medicine and Medical Specialties, Sapienza University, Rome, Italy

${ }^{4}$ Department of Neonatology, Catholic University of Rome, Italy

Tabacco Sara and Salvi Silvia are co-authors

Lanzone Antonio and De Carolis Maria Pia are co-seniors

*Corresponding author: Sara De Carolis, Department of Obstetrics and Gynaecology, Catholic University of Rome, Italy, Largo Agostino Gemelli 8, 00168 Rome, Italy, Tel: +39 06 30156774; E-mail: saradecarolis@libero.it, sara.decarolis@unicatt.it

Received date: June 09, 2016; Accepted date: July 20, 2016; Published date: July 25, 2016

Copyright: (C) 2016 Sara DC, et al. This is an open-access article distributed under the terms of the Creative Commons Attribution License, which permits unrestricted use, distribution, and reproduction in any medium, provided the original author and source are credited.

\section{Abstract}

Background: The $20-30 \%$ of women with antiphospholipid syndrome (APS) remains unable to give birth to healthy neonates despite the conventional treatment. The purpose of this review is to summarize literature on the predictors of poor pregnancy outcome in women affected by APS.

Results: History of pregnancy morbidity and/or thrombosis and the association with SLE are well known historybased predictive factors for pregnancy failure in women with APS. Moreover, laboratory findings associated with unsuccessful pregnancy outcome are lupus anticoagulant positivity, triple antiphospholipid antibodies (aPL) positivity, false-positive IgM for CMV and hypocomplementemia. The abnormal uterine arteries Doppler velocimetry results are confirmed to be strongly associated with poor maternal and feto-neonatal outcomes in APS pregnancies.

Conclusion: To correctly explore and identify these clinical and laboratory variables associated with pregnancy failure is a critical step in aiding clinicians to manage and counsel the women with APS. Finding the optimal combination therapy according to these risk factors to prevent the main maternal and feto-neonatal complications in APS pregnancies is warranted.

Keywords: Predictors; Pregnancy outcome; Antiphospholipid syndrome

\section{Introduction}

Prognosis of pregnancies in women with Antiphospholipid Syndrome (APS) has greatly improved over the past two decades. Conventional treatment based on low molecular weight heparin (LMWH) and low-dose aspirin (LDA) is associated with a rate of live birth of almost $80 \%$ [1-3]. Despite these encouraging results, some APS patients remain unable to give birth to healthy neonates.

Miscarriage, fetal loss and stillbirth represent some features that can occur at different stages of pregnancy. Moreover, some pregnancies may be complicated by preeclampsia, fetal growth restriction (FGR) and pre-term birth.

Several studies have been performed in order to identify risk factors predictive of complications despite the conventional treatment $[3,4]$.

Aim of this study is to review and to estimate the role of the different predictors of poor pregnancy outcome in women with APS.

\section{Pathophysiologic mechanisms of placental damage in APS}

Among the different pathogenic mechanisms involved in explaining maternal and fetal complications of APS pregnancies, the intraplacental thrombosis was traditionally suggested to be the main pathogenic event. A large series of studies have been attempted to demonstrate the ability of aPL to induce a general procoagulant state characterized by endothelial cell activation, inhibition of protein $\mathrm{C} / \mathrm{S}$ system, increased thromboxane synthesis, tissue factor activation and cytokine production $[5,6]$.

Furthermore, other studies demonstrate that antiphospholipid antibodies are able to interfere with the potent anticoagulant activity of annexin [7]. The syncytiotrophoblast naturally exteriorises phosphatidylserine, a trigger of contact-dependent coagulation. In normal pregnancies, exteriorised phosphatidylserine may be protected from maternal coagulation factors by annexin $\mathrm{V}$, a phosphatidylserinebinding protein that is thought to form a lattice-like shield over the surface of the syncytiotrophoblast. The annexin $\mathrm{V}$ shield may be disrupted in pregnancies affected by APS, as suggested by experiments performed in vitro, which have demonstrated that aPLs displace annexin $\mathrm{V}$ from the surface of placental explants or syncytialised trophoblasts $[8,9]$.

De Wolf et al. firstly published the histological reports of placental tissues from pregnancies complicated by APS founding that the intraluminal thrombosis could be detected in fifty percent of these placentae [10]. This hypothesis was subsequently supported by other histological findings of intervillous thrombosis, extensive villous fibrosis or marked infarction. More recently, in the placentae of women 
with APS, the following five features were observed, as well described by Viall et al; not only placental infarctions can be detected but also increased syncytial knots, decreased vasculosyncytial membranes, decidual inflammation and impaired spiral artery remodelling [11]. These different types of lesions suggest that multiple pathological events may occur in pregnancies complicated by APS and the thrombogenic state alone is not able to explain all the different mechanisms leading to pregnancy failure in APS.

Some studies in vitro demonstrated that antiphospholipid antibodies (aPL) adversely affect the trophoblast functions, impairing its invasion, differentiation and maturation, through mechanisms unrelated to thrombosis [12,13]. If an abnormal early trophoblast invasion is the candidate mechanism able to explain the first trimester pregnancy losses, on the other hand, second- and third-trimester fetal losses are more likely to be the results of a thrombotic damage on the uteroplacental vasculature.

Other mechanisms suggested in aPL-associated defective placentation are: direct cellular injury, apoptosis, inhibition of proliferation and syncytia formation, decreased GnRH-induced human chorionic gonadotrophin (hCG) production, and impaired invasiveness [14,15].

Moreover, the oxidative stress, by aPL cross-reaction with oxidized LDL, and the aPL mediated complement activation can be considered contributing factors in placental injury, suggesting an autoimmune inflammatory role in aPL related obstetrical complications $[16,17]$.

\section{Predictive value of uterine arteries Doppler velocimetry}

As regards to the clinical issue, in the last two decades many efforts have been performed to identify the best way to monitor and to manage these pregnancies. In this direction, several studies have been conducted to validate the predictive value of uterine arteries Doppler velocimetry in relation to pregnancy outcome.

Uterine arteries Doppler velocimetry provides a non-invasive indirect method of studying the uteroplacental circulation and strongly suggests impaired trophoblastic invasion of the placental bed before any clinical sign of preeclampsia or fetal growth restriction. At 22-24 weeks of pregnancy, the persistence of high resistances in the uterine arteries may reflect the failure of the uterine vasculature adaptation, thus being a risk factor for the consequent maternal and fetal pathologies [18]. The increase in flow resistance within the uterine arteries results in an abnormal waveform pattern, which is represented by either an increased bilateral resistance index ( $\mathrm{RI}=$ [peak systolic flow velocity - end diastolic flow velocity] / peak systolic flow velocity) or by the persistence, beyond 24-26 weeks of gestation, of unilateral or bilateral protodiastolic notch, which reflects failure of the second wave of trophoblastic invasion of the uteroplacental vasculature.

We firstly analyzed the role of Doppler velocimetry of uterine arteries in pregnancies complicated by APS [19]. 28 APS patients (17 with primary APS and seven with secondary APS) were analyzed. Enrolled women delivered 23 live infants $(82.1 \%)$ at $28-40$ weeks of gestation. Three infants weighed less than the tenth percentile (13\%). Five pregnancies $(21 \%)$ were complicated by preeclampsia and ten pregnancies $(43 \%)$ were complicated by non-proteinuric gestational hypertension. There were three first trimester miscarriages $(10.7 \%)$ and two fetal deaths at 19 and 25 weeks of gestation, respectively (7.1\%). Excluding miscarriages, color Doppler ultrasound examination of the uterine arteries was performed between 18 and 24 weeks of gestation. The lowest values of RI greater than the 90th percentile for gestational age best identified the pregnancies with the poorest fetal outcome in terms of mean week at delivery, mean neonatal birth weight, and mean neonatal birth weight percentile. As indicated by kappa values, the predictive ability of the lowest abnormal RI (>90th percentile for gestational age) was good for preeclampsia and for delivery $\leq 32$ weeks, and was excellent for neonatal birth weight less than 1750 g. In our study, color Doppler evaluation of uterine artery RI was a good tool for early identification of pregnancy at major risk for having preterm delivery, lower birth weight and lower birth weight percentile.

Other investigators [20] performed uterine arteries Doppler analysis between 19 and 34 weeks of gestation in 43 pregnancies complicated with APS. Uterine arteries were considered abnormal if the bilateral RI was greater than the 95th percentile for gestational age or demonstrated an early diastolic notch. In pregnancies with abnormal uterine artery Doppler waveforms, birth weight of less than tenth percentile and preterm delivery before 34 weeks of gestation were both statistically increased ( $p=0.045$ and $p=0.003$, respectively), three cases of severe preeclampsia and a case of placental abruption at 27 weeks were observed. There were no cases of preterm delivery or preeclampsia in 32 APS pregnancies with normal uterine artery Doppler velocimetry. In a subsequent report [21], 170 pregnant women with a history of $r$ current miscarriage in association with APS were recruited prospectively. Doppler examination of the uterine arteries was performed at 16-18 and 22-24 weeks of gestation. Uterine artery PI and the presence of early unilateral or bilateral diastolic notches were analyzed. There were 164 live births and six fetal losses. Of 164 live births, 11 (7\%) infants had birth weights below the 5th percentile and $17(10 \%)$ had birth weights below the 10th percentile. Preeclampsia occurred in 16 women $(10 \%)$. In the entire study population, uterine artery PIs at 16 or 24 weeks and uterine artery notching at 16 weeks had no predictive value for preeclampsia or SGA infants, while there was a statistically significant association between the persistence of bilateral uterine artery notching at 24 weeks and subsequent development of SGA infants and preeclampsia. Bilateral uterine artery notches at 22-24 weeks in predicting preeclampsia generated a high likelihood ratio for positive test (12.8; CI 2.2-75), sensitivity (75\%), specificity (94\%), and positive (75\%), and negative (94\%) predictive value. In predicting SGA infants, the corresponding figures were, respectively, 13.6 (CI 1.9-96), 80\%, 94\%, and $80 \%$ and $94 \%$. These results suggested that bilateral uterine artery notching at 22-24 weeks in predicting preeclampsia and SGA infant in women with aPL is a promising test.

In a similar way, Stone et al. showed in a cohort of 33 women with APS, that the positive predictive value of abnormal uterine artery Doppler profile for prediction of IUGR or preeclampsia was $67 \%$ with a negative predictive value of $93 \%$ [22].

Another prospective study [23], was performed to examine the predictive role of Doppler ultrasound examination in 116 pregnancies complicated with SLE and/or APS (44 SLE pregnancies, 24 secondary APS patients, and 32 primary APS patients). Sixteen out of 116 pregnancies ended in 12 fetal deaths and four embryonic losses, which occurred before the second-trimester fetal Doppler examination, so data from 100 pregnancies were analyzed. Seven fetal deaths (between 24 and 39 weeks) and one neonatal death occurred. In multivariate analysis, the only two predictors were abnormal end-diastolic umbilical artery Doppler flow at second trimester and history of thrombophlebitis. Adverse pregnancy outcomes occurred as following: preeclampsia/HELLP syndrome in seven cases, severe prematurity in 
two cases, and growth restriction in 14 cases. In multivariate analysis, the only predictor was the presence of a notched uterine artery at the second-trimester examination with an OR of 13.84 (95\% CI 3.4156.16, $\mathrm{p}=0.001$ ).

Another interesting prospective study was performed by Bats et al. [24]. One of the authors' objectives was to evaluate the predictive value of uterine artery Doppler examination, performed as soon as the first trimester of pregnancy (12-15 weeks of gestation). Thirty-three pregnancies complicated by APS were prospectively followed by monthly ultrasonographic assessment of fetal growth; uterine artery Doppler velocimetry at $12-15$ weeks, 22 weeks, and 32 weeks. In this high-risk population, seven recurrences of vascular pathology occurred: six cases of mild, isolated FGR and one case of preeclampsia associated with FGR requiring preterm delivery. No recurrence of second- or third-trimester fetal death was observed. In this population, there was a bilateral notch in $38 \%$ of cases during the first trimester (12-15 weeks); this finding was associated with a significantly lower neonatal birth weight compared to cases with absent or with a unilateral notch. The negative predictive value of uterine Doppler was more than $92 \%$ at $12-15$ weeks of gestation and remained high throughout pregnancy.

Despite the different inclusion criteria, the different Doppler parameters investigated, and the different maternal treatment and gestational age at the Doppler investigation, the good performance of the uterine arteries velocimetry as a negative predictive factor was reported by all the studies [19-25].

On the contrary, in case of abnormal uterine arteries Doppler velocimetry results, the importance of a careful surveillance of these pregnancies is highlighted for the highest risk of maternal and fetal complications. To date, the uterine arteries Doppler velocimetry in the second trimester resulted to be a useful tool for identifying APS pregnancies at risk for poor pregnancy outcome [25].

\section{Predictive value of false-positive CMV IgM antibodies}

Clinicians are aware that APS and other autoimmune diseases are often associated with false-positive serological tests for infections, such as toxoplasmosis, others, rubella, cytomegalovirus, herpes viruses (TORCH), human immunodeficiency virus (HIV), Lyme disease, and syphilis; serological diagnosis of infection may be hampered by changes in several components of the immune response which may lead to false-positive results in serological tests. These false-positive tests may reflect the non-specific activation of B lymphocytes [26]. The issue of false-positive IgM for infectious agents was introduced and discussed in different studies [27,28].

In patients with autoimmune disease, false-positive VDRL was firstly reported. [27]. Moreover, a significant increase in antibody titers to a number of viruses (such as rubella, measles, parainfluenza types 1, 2, and 3, reovirus type 2, Epstein-Barr virus, mumps, HIV 1, HCV) has been reported [29], without any clinical evidence of infection. The most studied infectious agent in this issue is cytomegalovirus (CMV): false-positive results for anti CMV IgM were described in autoimmune populations out of pregnancy $[30,31]$.

Several studies observed that in autoimmune diseases, the presence of TORCH IgM is associated to a worse evolution of the autoimmune disease itself [32]. Few studies focused on the possible relationship between false-positive results of the test for syphilis and pregnancy outcome in healthy women $[33,34]$.
Up to date, we clarified the relationship between false-positive IgM for CMV and pregnancy outcome in APS patients [35]. CMV IgM was more frequent in APS pregnancies than in healthy controls $(12.9 \%$ vs. $0.9 \% ; \mathrm{p}<0.0001)$. In APS pregnancies, both in primary and secondary APS, a poor pregnancy outcome in terms of a lower neonatal birth weight and a lower neonatal birth weight percentile was observed among women with CMV IgM false positivity in comparison with those without CMV IgM false positivity. Comparing APS pregnancies with CMV IgM false positivity and APS without false positivity, we found that in the first group the week of delivery was lower (mean \pm SD: $36 \pm 3$ versus $38 \pm 3$, p-value $=0,19$ ) such as the neonatal birth weight (mean \pm SD: $2386 \mathrm{~g} \pm 451$ versus $2871 \mathrm{~g} \pm 631, \mathrm{p}$-value $=0,05)$ and the neonatal birth weight percentile (mean \pm SD: $25 \pm 25$ versus 45 \pm 25 , p-value $=0,03$ ).

To date, these data suggest that the presence of CMV IgM false positivity could represent a novel prognostic factor for poor pregnancy outcome in APS patients, available before planning pregnancy or in the first trimester.

\section{Predictive value of hypocomplementemia}

As previously stated, the thrombotic phenomena alone cannot explain the obstetrical manifestations in APS syndrome. Actually, there is emerging evidence that the complement pathway may mediate the inflammatory fetal damage in APS in animal models [36-38].

An interesting report [39], documented an increased deposition of complement products $\mathrm{C} 4 \mathrm{~d}$ and $\mathrm{C} 3 \mathrm{~b}$ in placentas from APS patients rather than normal controls. These placental findings are evident even when the presence of aPL is clinically silent.

From a clinical point of view, hypocomplementemia has been found in a significant proportion of patients with primary APS (PAPS) out of pregnancy: it was associated with thrombosis in one study and with livedo reticularis and thrombocytopenia in another publication [40].

In order to investigate the predictive value of serum C3 and C4 complement component in pregnancy, a prospective study of 47 APS pregnancies was performed by our group [41]. Pregnancy outcome was analyzed in terms of: fetal loss, preterm delivery $(\leq 34$ gestational weeks), FGR, birth weight $<2500 \mathrm{~g}$ and preeclampsia. Week at delivery, neonatal birth weight and neonatal birth weight percentile were also investigated. Hypocomplementemia, positivity for anti-dsDNA and triple positivity for aPL were related to pregnancy outcome. Fortythree pregnancies ended in live births with a fetal loss rate of $8.5 \%$. Fetal death, preterm delivery and birth weight $<2500 \mathrm{~g}$ were associated with hypocomplementemia $(\mathrm{p}=0.019, \mathrm{p}=0.0002, \mathrm{p}<0.0001$, respectively). Lower neonatal birth weight, lower neonatal birth weight percentile and lower week at delivery were associated with hypocomplementemia $(\mathrm{p}<0.0001, \mathrm{p}=0.0003, \mathrm{p}<0.0001$, respectively) and with triple aPL positivity $(\mathrm{p}=0.008, \mathrm{p}=0.014, \mathrm{p}=0.03$, respectively). A poor pregnancy outcome was confirmed among PAPS pregnancies with hypocomplementemia. Multivariate analysis confirmed that hypocomplementemia was an independent predictor of lower neonatal birth weight $(\mathrm{p}=0.0001)$ and lower week at delivery $(\mathrm{p}=0.002)$.

Other investigators [42,43], evaluated in pregnancies complicated with PAPS, the association between serum complement levels (C3 and C4) and obstetric complications: fifty-seven pregnancies in primary APS were compared with a group of 175 healthy women. The PAPS group showed significantly lower levels of $\mathrm{C} 3$ and $\mathrm{C} 4$ in each trimester in comparison with healthy women, but no association was found between hypocomplementemia and the obstetric investigation 
evaluated by the authors. There is evidence that the complement system is a major contributor to the mechanisms of aPL-mediated damage, but, according to these authors, its predictive role on the final pregnancy outcome does not seem to be of major impact.

In the European Registry on Obstetric Antiphospholipid Syndrome (EUROAPS), a project by Alijotas-Reig et al. the complement pathway of 201 women with obstetric antiphospholipid syndrome was analyzed: 98 women showed decreased values of complementemia, such as low C4 levels or low C3 levels or low C4 and C3 levels [2].

Ruffatti et al. in a multicenter case-control study [4] compared APS patients with successful and unsuccessful pregnancy outcome: 410 pregnancies of women with PAPS were considered. The study focused on 57 unsuccessful pregnancies (considered the study populations) and 57 successful pregnancies (considered the control population) matched for age and therapy. Lower C3 and C4 levels at baseline and at the end of pregnancy both found to be significantly correlated with pregnancy failure ( $\mathrm{p}=0.004$ and $\mathrm{p}=0.046$, respectively) by univariate analysis, but not by multivariate analysis. In the study by Ruffatti, pregnancy failure was defined as fetal death, premature birth $<34$ weeks of gestation associated to placental insufficiency and spontaneous abortion.

These data suggest that hypocomplementemia could be considered a prognostic factor for pregnancy outcome in APS patients.

\section{Predictive value of history of pregnancy morbidity, thrombosis and association with SLE}

In our study from 1993, including 25 pregnancies with APS, the presence of SLE, pre-pregnancy medical disorders and positivity of lupus anticoagulant did not relate with pregnancy outcome, probably because of the smallness of sample size [19]. However different subsequent studies clarified in APS patients that the association with SLE and/or the history of thromboembolism are risk factors for poor pregnancy outcome.

Ruffatti et al. [4] in their multicenter case-control study demonstrated that both the presence of SLE and the history of thrombosis and pregnancy morbidity are major independent risk factors for pregnancy failure in APS. In fact, the presence of SLE or other autoimmune diseases (OR 6.0; 95\% CI 1.7, 20.8; $\mathrm{P}=0.01$ ) and the history of both thrombosis and pregnancy morbidity (OR 12.1; 95\% CI $1.3,115.3 ; \mathrm{P}=0.03$ ) resulted all related to pregnancy failure by multivariate analysis.

Rezk et al. [44] performed a prospective observational study that included 162 patients with primary APS who were divided into two groups, group 1 with previous thrombosis $(n=74)$ and group 2 without previous thrombosis $(n=88)$. Patients were followed from the beginning of pregnancy until delivery. There was a significant difference among the two groups with higher rate of miscarriage $(\mathrm{p}<0.05)$, maternal venous thromboembolism $(\mathrm{p}<0.001)$, intrauterine fetal demise and neonatal death $(\mathrm{p}<0.05)$ in group 1 . However the two groups did not differ in the rate of preeclampsia, eclampsia, postpartum hemorrhage, prematurity and admission to neonatal intensive care unit $(\mathrm{p}>0.05)$. By both univariate and multivariate analyses, previous thrombosis was confirmed as independent predictors of pregnancy loss (Crude Odd's Ratio 1.57).

The comorbidity, as the presence of SLE or other autoimmune disease, as well as the history of pregnancy morbidity and thrombosis, are adjunctive risk factors for pregnancy outcome.

\section{Predictive value of triple aPL positivity and presence of lupus anticoagulant}

In our preliminary results on APS [19], the mean neonatal birth weight was found to be significantly lower in pregnancies with three positive tests for aPL respect to pregnancies without the three positive assays at conception $(\mathrm{p}=0.004)$.

Then the influence of triple aPL positivity on pregnancy outcome was confirmed by a large body of evidence demonstrating the correlation between triple positivity for anti- $32 \mathrm{GPI}$ antibodies, antiaCL antibodies and lupus anticoagulant positivity with poor obstetrical outcome. Ruffatti et al. [4] reported that APS women with unsuccessful pregnancies had a statistically significant increased prevalence of triple aPL positivity by univariate analysis. Moreover, in the multivariate analysis triple aPL positivity was confirmed to be an independent risk factor for pregnancy failure. Alijotas et al, in the European Registry on Obstetric Antiphospholipid Syndrome (EUROAPS), validated the association between the triple aPL positivity and recurrent miscarriage ( $\geq 3$ miscarriages $<10$ weeks) and fetal loss/stillbirth ( $>1$ loss, over 10 weeks) ( $\mathrm{p}=0.0505$ and $\mathrm{p}=0.0033$, respectively). Early-onset preeclampsia/HELLP and prematurity were associated with lupus anticoagulant positivity ( $\mathrm{p}=0.0016$ and $\mathrm{p}=0.0005$, respectively), and FGR was associated to both triple aPL positivity and lupus anticoagulant positivity ( $\mathrm{p}=0.0693$ and $\mathrm{p}=0.0151$ respectively) [2]. Additionally, Retz et al. confirmed the triple aPL positivity as independent predictor of pregnancy loss by univariate and multivariate analysis (Crude Odd's Ratio 1.29) [44].

More recently, the central role of triple aPL positivity in pregnancy was confirmed by the PROMISSE study. This is a multicenter, prospective, observational study of pregnancy outcome in women with APS and/or SLE [45]. Forty-four aPL positive patients were analyzed. Patients were followed monthly until delivery and aPL were tested at first, second and third trimesters of pregnancy and at 12 weeks postpartum. LA was present in $69 \%$ of patients with adverse pregnancy outcomes compared with $27 \%$ of patients with successful pregnancy $(\mathrm{p}=0.01)$, defined as fetal death after 12 weeks of gestation, neonatal death, delivery prior to 36 weeks of gestation due to preeclampsia or placental insufficiency and small for gestational age. Furthermore, these authors found that the triple aPL positivity was associated with good pregnancy outcome in only one case among thirty-one.

In a more recently published analysis of data from PROMISSE study, the importance of the LA positivity in the first trimester as predictor of adverse pregnancy outcome has been extensively highlighted, concluding that the early assessment of the LA positivity is enough to assess the individual risk of each patient. Changes in aPL levels or aPL status later in pregnancy were not associated with adverse pregnancy outcome. Furthermore, the authors described that the BMI $>30$, history of thrombosis, but not history of obstetrical complications, were also associated with adverse pregnancy outcome [46].

In conclusion, the triple aPL positivity is validated as a good predictor of poor pregnancy outcome in APS pregnancies.

\section{Conclusion}

Presence of SLE, history of pregnancy morbidity and previous thrombosis are history-based predictive factors for poor pregnancy outcome in women with APS (Table 1). 
Citation: Tabacco S, Salvi S, De Carolis S, Botta A, Ferrazzani, S et al. (2016) Predictors of Pregnancy Outcome in Antiphospholipid Syndrome: A Review. J Allergy Ther 7: 239. doi:10.4172/2155-6121.1000239

Page 5 of 7

From a laboratoristic point of view, findings of LA positivity triple hypocomplementemia are important predictors of poor pregnancy aPL positivity, false-positive CMV IgM antibodies and outcome (Table 1).

\begin{tabular}{|c|c|c|c|}
\hline Author & Year & Predictor & Pregnancy Outcome \\
\hline Caruso et al. [19] & 1993 & Uterine Artery Doppler Velocimetry $\left(\mathrm{RI}>90^{\text {th }} \mathrm{pc}\right)$ & $\begin{array}{l}\downarrow \text { Mean week at delivery } \\
\downarrow \text { Mean birth weight and birth weight percentile } \\
\uparrow \text { Preeclampsia } \\
\uparrow \text { Preterm delivery (<32 weeks) }\end{array}$ \\
\hline Farrel et al. [20] & 2001 & $\begin{array}{l}\text { Uterine Artery Doppler Velocimetry }\left(\mathrm{R} I>95^{\text {th }} \mathrm{pc}\right. \\
\text { or Notch) }\end{array}$ & $\begin{array}{l}\uparrow \text { Preeclampsia } \\
\uparrow \text { Preterm delivery (<34 weeks) }\end{array}$ \\
\hline Venkat-Raman et al. [21] & 2001 & $\begin{array}{l}\text { Uterine Artery Doppler Velocimetry (Bilateral } \\
\text { Notches) }\end{array}$ & $\begin{array}{l}\uparrow \text { Preeclampsia } \\
\uparrow \text { Birth Weight }<10^{\text {th }} p c\end{array}$ \\
\hline Bats et al. [24] & 2004 & $\begin{array}{l}\text { Uterine Artery Doppler Velocimetry (Bilateral } \\
\text { Notches) }\end{array}$ & $\downarrow$ Mean birth weight \\
\hline Stone et al. [22] & 2004 & Uterine Artery Doppler Velocimetry & $\begin{array}{l}\uparrow \text { Preeclampsia } \\
\uparrow \text { IUGR }^{*}\end{array}$ \\
\hline Le Ti Huong et al. [23] & 2006 & $\begin{array}{l}\text { Uterine Artery Doppler Velocimetry (Bilateral } \\
\text { Notches) }\end{array}$ & $\begin{array}{l}\uparrow \text { Preeclampsia } \\
\uparrow \text { IUGR }^{*}\end{array}$ \\
\hline De Carolis et al. [35] & 2012 & False-positive IgM for Cytomegalovirus & $\downarrow$ Mean birth weight and birth weight percentile \\
\hline De Carolis et al. [41] & 2012 & Low C3 and/or C4 serum levels & $\begin{array}{l}\downarrow \text { Mean week at delivery } \\
\downarrow \text { Mean birth weight and birth weight percentile } \\
\uparrow \text { Fetal Death } \\
\uparrow \text { Birth weight }<2500 \mathrm{~g} \\
\uparrow \text { Preterm delivery ( } \leq 34 \text { weeks) }\end{array}$ \\
\hline Ruffatti et al. [4] & 2011 & $\begin{array}{l}\text { Association with SLE } \\
\text { History of both pregnancy morbidity and } \\
\text { thrombosis }\end{array}$ & $\uparrow$ Unsuccessful pregnancies§ \\
\hline Rezk et al. [44] & 2016 & Previous thrombosis & $\begin{array}{l}\uparrow \text { Miscarriage } \\
\uparrow \text { Fetal loss/Intrauterine death }\end{array}$ \\
\hline Caruso et al. [19] & 1993 & Three positive test for aPL & $\downarrow$ Mean birth weight \\
\hline Ruffatti et al. [4] & 2011 & Triple aPL positivity & $\uparrow$ Unsuccessful pregnancies§ \\
\hline Alijotas-Reig et al. [2] & 2015 & Triple aPL positivity & $\begin{array}{l}\uparrow \text { Recurrent miscarriage } \\
\uparrow \text { Fetal loss/Intrauterine death } \\
\uparrow \text { IUGR }^{*}\end{array}$ \\
\hline Rezk et al. [44] & 2016 & Triple aPL positivity & $\begin{array}{l}\uparrow \text { Miscarriage } \\
\uparrow \text { Fetal loss/Intrauterine death }\end{array}$ \\
\hline Ruffatti et al. [4] & 2011 & LA positivity & $\uparrow$ Unsuccessful pregnancies§ \\
\hline Alijotas-Reig et al. [2] & 2015 & LA positivity & $\begin{array}{l}\uparrow \text { Preeclampsia/HELLP } \\
\uparrow \text { IUGR }^{*}\end{array}$ \\
\hline Yelnik et al. [45] & 2016 & LA positivity & $\uparrow$ Adverse pregnancy outcome $e^{\S \S}$ \\
\hline
\end{tabular}

Table 1: Predictors of Pregnancy Outcome in Antiphospholipid Syndrome. ${ }^{*}$ IUGR: intrauterine growth restriction; ${ }^{\circledR}$ Unsuccessful pregnancies: fetal death, premature birth and spontaneous abortion; ${ }^{\$ \$}$ Adverse pregnancy outcome (APOs): fetal death after 12 weeks of gestation, neonatal death, delivery prior to 36 weeks of gestation due to preeclampsia or placental insufficiency and small for gestational age.

All the aforementioned risk factors are available at the beginning of pregnancy or before planning pregnancy. Differently, the Doppler 
investigation of uterine artery and fetal vessels are available at least in the second trimester, useful to monitor fetal wellbeing throughout pregnancy.

Identifying these variables associated with pregnancy failure and pregnancy complications is an important step in aiding clinicians to manage and counsel the women with APS.

In the future finding the optimal combination therapy according to these risk factors to prevent the main maternal and feto-neonatal complications in APS pregnancies is warranted.

\section{References}

1. Carmona F, Font J, Azulay M, Creus M, Fábregues F, et al. (2001) Risk factors associated with fetal losses in treated antiphospholipid syndrome pregnancies: a multivariate analysis. Am J Reprod Immunol 46: 274-279.

2. Alijotas-Reig J, Ferrer-Oliveras R, Ruffatti A, Tincani A, Lefkou E, et al. (2015) The European Registry on Obstetric Antiphospholipid Syndrome (EUROAPS): A survey of 247 consecutive cases. Autoimmun Rev 14: 387-395.

3. De Carolis S, Botta A, Santucci S, Garofalo S, Martino C, et al. (2010) Predictors of pregnancy outcome in antiphospholipid syndrome: a review. Clin Rev Allergy Immunol 38: 116-124.

4. Ruffatti A, Tonello M, Visentin MS, Bontadi A, Hoxha A, et al. (2011) Risk factors for pregnancy failure in patients with anti-phospholipid syndrome treated with conventional therapies: a multicentre, case-control study. Rheumatology (Oxford) 50: 1684-1689.

5. Branch DW (2004) Antiphospholipid syndrome and fetal compromise. Thromb Res 114: 415-418.

6. Ogishima D, Matsumoto T, Nakamura Y, Yoshida K, Kuwabara Y (2000) Placental pathology in systemic lupus erythematosus with antiphospholipid antibodies. Pathol Int 50: 224-229.

7. Rand JH, Wu XX, Quinn AS, Chen PP, McCrae KR, et al. (2003) Human monoclonal antiphospholipid antibodies disrupt the annexin A5 anticoagulant crystal shield on phospholipid bilayers: evidence from atomic force microscopy and functional assay. Am J Pathol 163: 11932000.

8. Rand JH, Wu XX, Quinn AS, Ashton AW, Chen PP, et al. (2010) Hydroxychloroquine protects the annexin A5 anticoagulant shield from disruption by antiphospholipid antibodies: evidence for a novel effect for an old antimalarial drug. Blood 115: 2292-2299.

9. Wu XX, Guller S, Rand JH (2011) Hydroxychloroquine reduces binding of antiphospholipid antibodies to syncytiotrophoblasts and restores annexin A5 expression. AmJ Obstet Gynecol 205: 577-514.

10. De Wolf F, Carreras LO, Moerman P, Vermylen J, Van Assche A, et al. (1982) Decidual vasculopathy and extensive placental infarction in a patient with repeated thromboembolic accidents, recurrent fetal loss, and a lupus anticoagulant. Am J Obstet Gynecol 142: 829-834.

11. Viall CA, Chamley LW (2015) Histopathology in the placentae of women with antiphospholipid antibodies: A systematic review of the literature. Autoimmun Rev 14: 446-471.

12. Chamley LW, Duncalf AM, Mitchell MD, Johnson PM (1998) Action of anticardiolipin and antibodies to beta2-glycoprotein-I on trophoblast proliferation as a mechanism for fetal death. Lancet 352: 1037-1038.

13. Jovanović M, Bozić M, Kovacević T, Radojcić L, Petronijević M, et al. (2010) Effects of anti-phospholipid antibodies on a human trophoblast cell line (HTR-8/SVneo). Acta Histochem. 112: 34-41.

14. Lyden TW, Vogt E, Ng AK, Johnson PM, Rote NS (1992) Monoclonal antiphospholipid antibody reactivity against human placental trophoblast. J Reprod Immunol 22: 1-14.

15. Sebire NJ, Fox H, Backos M, Rai R, Paterson C, et al. (2002) Defective endovascular trophoblast invasion in primary antiphospholipid antibody syndrome-associated early pregnancy failure. Hum Reprod 17: 10671071.
16. Pavan L, Tsatsaris V, Hermouet A, Therond P, Evain-Brion D, et al. (2004) Oxidized low-density lipoproteins inhibit trophoblastic cell invasion. J Clin Endocrinol Metab 89:1969-1972.

17. Holers VM, Girardi G, Mo L, Guthridge JM, Molina H, et al. (2002) Complement C3 activation is required for antiphospholipid antibodyinduced fetal loss. J Exp Med 195: 211-220.

18. Carbillon L, Uzan M, Uzan S (2000) Pregnancy, vascular tone, and maternal hemodynamics: a crucial adaptation. Obstet Gynecol Surv 55: 574-581.

19. Caruso A, De Carolis S, Ferrazzani S, Valesini G, Caforio L, et al. (1993) Pregnancy outcome in relation to uterine artery flow velocity waveforms and clinical characteristics in women with antiphospholipid syndrome. Obstet Gynecol 82: 970-977.

20. Farrell T, Dawson T (2001) Can uterine artery Doppler velocimetry predict adverse pregnancy outcome in women with antiphospholipid syndrome? Acta Obstet Gynecol Scand 80: 609-610.

21. Venkat-Raman N, Backos M, Teoh TG, Lo WT, Regan L (2001) Uterine artery Doppler in predicting pregnancy outcome in women with antiphospholipid syndrome. Obstet Gynecol 98: 235-242.

22. Stone S, Hunt BJ, Khamashta MA, Bewley SJ, Nelson-Piercy C (2005) Primary antiphospholipid syndrome in pregnancy: an analysis of outcome in a cohort of 33 women treated with a rigorous protocol. J Thromb Haemost 3: 243-245.

23. Le Thi Huong D, Wechsler B, Vauthier-Brouzes D, Duhaut P, Costedoat $\mathrm{N}$, et al. (2006) The second trimester Doppler ultrasound examination is the best predictor of late pregnancy outcome in systemic lupus erythematosus and/or the antiphospholipid syndrome. Rheumatology (Oxford) 45: 332-338.

24. Bats AS, Lejeune V, Cynober E, Safar E, Gonzales M, et al. (2004) Antiphospholipid syndrome and second- or third-trimester fetal death: follow-up in the next pregnancy. Eur J Obstet Gynecol Reprod Biol 114: 125-129.

25. De Carolis S, Botta A, Garofalo S, Ferrazzani S, Martino C, et al. (2007) Uterine artery velocity waveforms as predictors of pregnancy outcome in patients with antiphospholipid syndrome: a review. Ann N Y Acad Sci 1108: 530-539.

26. Ter Borg EJ, Horst G, Hummel E, Limburg PC, Kallenberg CG (1991) Rises in anti-double stranded DNA antibody levels prior to exacerbations of systemic lupus erythematosus are not merely due to polyclonal B cell activation. Clin Immunol Immunopathol 59: 117-128.

27. Haserik JR, Long R (1952) Systemic lupus erythematosus preceded by false-positive serologic tests for syphilis: presentation of five cases. Ann Intern Med 37: 559-565.

28. Miendje Deyi Y, Goubau P, Bodéus M (2000) False-positive IgM antibody tests for cytomegalovirus in patients with acute Epstein-Barr virus infection. Eur J Clin Microbiol Infect Dis 19: 557-560.

29. Rothfield NF, Evans AS, Niederman JC (1973) Clinical and laboratory aspects of raised virus antibody titres in systemic lupus erythematosus. Ann Rheum Dis 32: 238-246.

30. Cannavan FP, Costallat LT, Bértolo MB, Rossi CL, Costa SC (1998) False positive IgM antibody tests for human cytomegalovirus (HCMV) in patients with SLE. Lupus 7: 61-62.

31. Stratta P, Colla L, Santi S, Grill A, Besso L, et al. (2002) IgM antibodies against cytomegalovirus in SLE nephritis: viral infection or aspecific autoantibody? J Nephrol 15: 88-92.

32. Su BY, Su CY, Yu SF, Chen CJ (2007) Incidental discovery of high systemic lupus erythematosus disease activity associated with cytomegalovirus viral activity. Med Microbiol Immunol 196: 165-70.

33. Lau R, Forster GE (1987) False positive results of tests for syphilis and outcome of pregnancy. Br Med J (Clin Res Ed) 295: 925.

34. Henriksen R, Sögaard PE, Grennert L, Hansen BU, Manthorpe R, et al. (1989) Autoimmune antibodies and pregnancy outcome in women with false-positive syphilis test results. A retrospective controlled investigation of women from 5170 deliveries. Acta Obstet Gynecol Scand 68: 537-540. 
Citation: Tabacco S, Salvi S, De Carolis S, Botta A, Ferrazzani, S et al. (2016) Predictors of Pregnancy Outcome in Antiphospholipid Syndrome: A Review. J Allergy Ther 7: 239. doi:10.4172/2155-6121.1000239

Page 7 of 7

35. De Carolis S, Santucci S, Botta A, Salvi S, Degennaro VA, et al. (2012) The relationship between TORCH complex false positivity and obstetric outcome in patients with antiphospholipid syndrome. Lupus 21: 773-775.

36. Holers VM, Girardi G, Mo L, Guthridge JM, Molina H, et al. (2002) Complement C3 activation is required for antiphospholipid antibodyinduced fetal loss. J Exp Med 195: 211-220.

37. Pierangeli SS, Girardi G, Vega-Ostertag M, Liu X, Espinola RG, et al. (2005) Requirement of activation of complement C3 and C5 for antiphospholipid antibody-mediated thrombophilia. Arthritis Rheum 52: 2120-2124.

38. Salmon JE, Girardi G (2008) Antiphospholipid antibodies and pregnancy loss: a disorder of inflammation. J Reprod Immunol 77: 51-56.

39. Shamonki JM, Salmon JE, Hyjek E, Baergen RN (2007) Excessive complement activation is associated with placental injury in patients with antiphospholipid antibodies. Am J Obstet Gynecol 196:167.

40. Carbone J, Orera M, Rodríguez-Mahou M, Rodríguez-Pérez C, SánchezRamón S, et al. (1999) Immunological abnormalities in primary APS evolving into SLE: 6 years follow-up in women with repeated pregnancy loss. Lupus 8: 274-278.

41. De Carolis S, Botta A, Santucci S, Salvi S, Moresi S, et al. (2012) Complementemia and obstetric outcome in pregnancy with antiphospholipid syndrome. Lupus 21: 776-778.
42. Reggia R, Ziglioli T, Andreoli L, Bellisai F, Iuliano A, et al. (2012) Primary anti-phospholipid syndrome: any role for serum complement levels in predicting pregnancy complications? Rheumatology (Oxford) 51: 2186-2190.

43. De Carolis S, Botta A, Salvi S, Del Sordo G, De Carolis MP (2013) Complementemia and obstetric outcome in Antiphospholipid syndrome pregnancies. Letters to Rheumatology.

44. Rezk M, Dawood R, Badr H (2016) Maternal and fetal outcome in women with antiphospholipid syndrome: a three-year observational study. J Matern Fetal Neonatal Med 3: 1-5.

45. Yelnik CM, Laskin CA, Porter TF, Branch DW, Buyon JP, et al. (2016) Lupus anticoagulant is the main predictor of adverse pregnancy outcomes in aPL-positive patients: validation of PROMISSE study results. Lupus Sci Med 3: e000131.

46. Yelnik CM, Porter TF, Branch DW, Laskin CA, Merrill JT, et al. (2016) Changes in Antiphospholipid Antibody Titers during Pregnancy: Data from the PROMISSE Study. Arthritis Rheumatol 18. 